\title{
La teoría del reconocimiento de Axel Honneth: un bosquejo moral de las formas de menosprecio social*
}

\author{
[Artículos]
}

Víctor Manuel Espiter Villa ${ }^{* *}$

Fecha de entrega: 15 de diciembre de 2020

Fecha de evaluación: 30 de abril de 2021

Fecha de aprobación: 18 de mayo de 2021

Citar como:

Espiter Villa, V. M. (2021). La teoría del reconocimiento de Axel Honneth: un bosquejo moral de las formas de menosprecio social. Cuadernos de Filosofía Latinoamericana, 42(125). https://doi.org/10.15332/25005375.6372

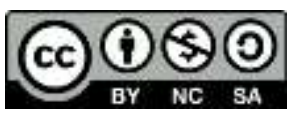

\section{Resumen}

En este artículo se establecen los criterios conceptuales que le permiten a Honneth dilucidar la idea de la reificación como un olvido de reconocimiento manifestado en formas de menosprecio que, al develar el sometimiento de individuos a situaciones de violencia, desposesión de derechos y deshonra, conducen hacia la necesidad de emprender una

\footnotetext{
* Este texto es producto de la investigación realizada por el profesor Espiter en su proyecto de grado de maestría, en el que se subrayan las luchas por el reconocimiento descritas por Axel Honneth como consecuencia de la patología social del menosprecio que, impidiendo fundamentar relaciones enmarcadas en la praxis del amor, el derecho y la solidaridad, dificulta la implementación de horizontes morales normativos que garanticen la resignificación humana. ** Filósofo, Magister en filosofía, Docente de planta adscrito a la Secretaría de Educación de Bolívar, Catedrático del Seminario Provincial San Carlos Borromeo, miembro del grupo de investigación Studia de la Universidad del Norte de Barranquilla. Correo electrónico: spitternov25@hotmail.com; ORCID: https://orcid.org/0000-0002-1852-1897
} 
lucha por el reconocimiento que, enmarcado en unos horizontes morales de carácter normativos, conlleven la praxis del amor, el derecho y la solidaridad como esferas imprescindibles para lograr la resignificación humana.

Palabras clave: Honneth, menosprecio, objetivación, olvido del reconocimiento, reconocimiento, reificación.

\section{Axel Honneth's Theory of Recognition: A Moral Sketch of Forms of Social Contempt}

\section{Abstract}

This article establishes the conceptual criteria that allow Honneth to elucidate the idea of reification as a forgetfulness of recognition manifested in forms of contempt that, by revealing the subjection of individuals to situations of violence, dispossession of rights, and dishonor, lead to the need to undertake a struggle for recognition that, framed within normative moral horizons, entails the praxis of love, law, and solidarity as essential spheres to achieve human resignification.

Keywords: Honneth, contempt, objectification, forgetfulness of recognition, recognition, reification.

\section{Introducción}

En esta reflexión, se establecerá la forma en que Honneth (1997), estudiando la concepción moderna de la realidad y destacando el bosquejo social desarrollado por Lukács (1970), observa los errores conceptuales en los que se ha incurrido frente a la necesidad de explicar los procesos de reificación social, puesto que se restringe el análisis de la cosificación al resultado de la comprensión fenoménica del entorno y a las condiciones de objetivación sufridas por los individuos, dejando de lado que el maltrato, la humillación y la desvalorización de lo humano se deben a un olvido del 
reconocimiento que, manifestado en formas de menosprecio, ocasiona el debilitamiento de la confianza, el irrespeto y la pérdida del autoestima. En esta dinámica, para establecer los criterios conceptuales que permiten dilucidar la idea de la reificación como el olvido de reconocimiento, Honneth (1997), en primer lugar, apoyado en la categoría apriorística de cura esbozada por Heidegger (1997), señala, de manera explícita, que, a diferencia de lo que se pensaba en el contexto de la filosofía moderna y más allá de la concepción social señalada por Lukács (1970), existe en el Dasein una preeminencia de lo precognitivo sobre los cognitivo, debido a que las experiencias de interacción se constituyen en condición de posibilidad del desarrollo de la cognición.

En segundo lugar, tomando las investigaciones de la psicología evolutiva, Honneth (1997) sustenta que, antes de asumir procesos comprensivos, el sujeto entabla situaciones de interacción simbiótica con una persona de referencia, al que concibe como la figura social que le conmina a instituirse en un sujeto reconocido. Esto indica que el olvido del reconocimiento, de acuerdo con lo propuesto por Honneth (1997), no sería otra cosa que desatender la presencia del otro como un sujeto que tiene un rol significativo en la construcción de lo social y, por lo cual, es tratado con menosprecio, ocasionando un quebranto moral expresado en términos de reificación.

En tercer lugar, la comprensión de las formas de menosprecio como obstáculo para la implementación del fenómeno moral permite explicar que los actos que producen violencia, desposesión de derechos y deshonra en la condición física y psicológica del sujeto desencadenan en un proceso de lucha. En procura de la resignificación humana, este proceso propicia la construcción de una eticidad social que, permitiendo la autorrealización individual y el arraigo a la construcción de una normatividad universal, 
garantice un reconocimiento social que, desde la praxis del amor, el derecho y la solidaridad, construya sujetos con autoestima, respetados socialmente y valorados en su condición humana.

\section{Honneth y la crítica a la noción de sujeto-objeto en la modernidad}

El escenario en el que se circunscribe la modernidad representa para

Honneth el espacio preciso para que se fragüen procesos de reificación, toda vez que tanto la realidad circundante como el sujeto de la interacción se someten a las propiedades de la objetivación. Por ello, Honneth (2007) expresa que "la filosofía moderna se ha topado siempre con antinomias irresolubles porque, debido a su arraigo en la cultura cotidiana reificada, ha quedado atrapada en el esquema de oposición entre sujeto - objeto" 1 (p. 39).

La anterior idea se refleja en las premisas teóricas de las corrientes filosóficas modernas, ya que asumen que la percepción fenoménica de la realidad quedó supeditada a las condiciones externas y formales de los objetos (Heidegger, 1997), precisamente porque se concibe al sujeto como conciencia receptiva del ente y, a su vez, se comprende el mundo como una entidad material que es concebida a partir de la contemplación de un espectador sin influencia. Ello indica que, desde Descartes, Hume y Kant ${ }^{2}$,

\footnotetext{
${ }^{1}$ La crítica heideggeriana a la filosofía, de manera especial a la modernidad, se ciñe al olvido de la pregunta por el ser, en la medida en que el ser no es asumido como aquello que determina al ente en cuanto ente, sino que se le confieren atributos del ente (Heidegger, 1997), estableciendo la relación epistémica sujeto-objeto como eje central de la comprensión del mundo.

${ }^{2}$ Cuando se analizan las categorías sujeto-objeto desde Descartes, Hume y Kant, se debe señalar que en Descartes el sujeto cognoscente es la sustancia del yo que tiene como esencia al pensamiento. Las cualidades cognitivas del cogito cartesiano le permiten tener cierta preeminencia sobre las condiciones mecánicas de la sustancia del mundo, develando que este es susceptible de ser conocido por las facultades intelectivas del sujeto. En el caso de Hume, el sujeto representa la naturaleza humana en términos de facultades cognitivas que son determinadas por las condiciones empírico-experimentales que le permiten percibir un fenómeno particular y, por ende, tener una idea de este. En el pensamiento de Kant, las facultades del sujeto trascendental se definen a partir de unos principios a priori del entendimiento y de las intuiciones a priori del espacio y el tiempo, los cuales constituyen el fundamento trascendental que hace posible el conocimiento (Rojas, 2013).
} 
se percibe la forma en que los modernos "exploran el contacto con el mundo desde la perspectiva de un observador externo y separado del mundo" (Escudero, 2016, p. 171), mostrando así que el proceso epistemológico se sustenta formalmente a partir del dualismo que gravita entre lo cognoscente y lo cognoscible.

Así, cuando se supone que las posibilidades existenciales de las cosas dependen de los procesos cognitivos, quiere decir que la razón de ser de un sujeto está determinada por la contemplación del objeto. De este modo, se hace necesario concebir las propiedades del acto cognoscente a partir de la concepción de la naturaleza como ente cognoscible que, por sus condiciones fenoménicas, es percibida por el hombre en cuanto ente que conoce. En ese sentido se denota que el proceso del conocimiento mismo reposa en el interior del hombre, debido a las connotaciones cognitivas que le revisten. No obstante, las condiciones incorpóreas del conocimiento hacen que este se conciba como algo imperceptible, que está ahí y que se encuentra dentro del sujeto que conoce (Heidegger, 1997).

Para establecer una precisión conceptual sobre la "esfera interior" en donde reposa el conocimiento, Honneth observa que Heidegger, apoyado en la noción apriorística de cura3, plantea "que el conocimiento es una modalidad de ser del Dasein en cuanto estar-el-mundo, esto es, que tiene su fundamento óntico en esta constitución del ser" (Heidegger, 1997, p 87). Lo anterior permite develar que el conocimiento no se prefigura como la manera en que el Dasein sale fuera de sí para ejecutar el acto de conocer, sino que, estando siempre fuera, se anticipa al conocer mismo.

\footnotetext{
${ }^{3}$ Cuando Heidegger utiliza el término cura no se refiere a una acción concreta sino a la condición ontológica, sin contenidos, que se constituye en una estructura puramente formal (Escudero, 2016). Dicha estructura se da existenciariamente a priori, toda vez que en todo comportamiento fáctico del Dasein existe desde siempre un arquetipo originario que se convierte en su fundamento (Heidegger, 1997). En ese sentido, la cura en Heidegger es la unidad originaria de la existenciariedad a partir del cual se puede definir el ser del ser ahí (Murueta, 2009).
} 
Dicho en términos de Heidegger (1997), "el Dasein no sale de su esfera interna, en la que estaría primeramente encapsulado, sino que, por su modo primario de ser, ya está siempre 'fuera', junto a un ente que comparece en el mundo ya descubierto cada vez" (p. 88).

La connotación que le da Heidegger al Dasein de anticiparse al conocer mismo permite descubrir la preeminencia de la ontología sobre la epistemología, puesto que "antes de que el Dasein conozca el mundo de manera teorética, existe ya en la apertura ateorética del mundo en medio de los entes que comparecen ateoréticamente en el mundo circundante ateoréticamente descubierto" (Escudero, 2016, p. 173). Así, el fuera de sí del Dasein que antecede los procesos del conocimiento, lejos de ser una cuestión ocasional y circunstancial, es algo constitutivo del ser, lo cual indica que lo teórico-epistemólogo ocurre posterior a la apertura ateorética del ser.

En este orden de ideas, se puede inferir que, más allá del formalismo de los procesos cognoscentes, son las connotaciones ateoréticas del ser lo que le permiten tener un involucramiento existencial y una participación auténtica en la vida cotidiana. En esta perspectiva, desde la interpretación honnethiana del pensamiento de Heidegger, puede inferirse que "la ejecución de la vida cotidiana está abierta para la existencia, y nos enfrentamos a esta no como sujetos cognoscentes, sino que la existencia es un campo de significación práctica en el cual estamos involucrados" (Chuca, 2011, p. 10).

\section{Honneth: la preeminencia del reconocimiento sobre el conocimiento}

Luego del análisis de los presupuestos de Heidegger (1997) sobre el dualismo sujeto-objeto que se impone en la modernidad, la intención de Honneth (1997) de concebir una realidad precognitiva que justifica la 
preeminencia de lo práctico sobre lo teórico le permite, en última instancia, emprender una reflexión sobre la teoría del reconocimiento entendida como realidad anterior a la comprensión teórico-epistémica del mundo. Así, el reconocimiento, al ser "la manifestación expresiva del hecho de quedar descentrado un individuo, que efectuamos teniendo en cuenta el valor de una persona" (Honneth, 2011, p. 180), permite recuperar el sentido de aquellas experiencias significativas que evitan que las relaciones intersubjetivas se restrinjan a lo eminentemente fenoménico.

En consonancia con lo anterior, resulta importante señalar que la prerrogativa de lo práctico sobre lo teórico permite "fundamentar la tesis de que en la relación del hombre consigo mismo y con el mundo, una postura de apoyo, de reconocimiento, precede, tanto en lo genético como en lo categorial, a todas las otras actitudes" (Honneth, 2007, p. 51), dejando sin piso la pretensión moderna de orientar las condiciones de la vida humana hacia la comprensión fenoménica del entorno que suprimiría cualquier interés existencial.

Para justificar la idea de la preeminencia del reconocimiento sobre el conocimiento, Honneth (2007) se vale específicamente de la psicología evolutiva, pues señala que existe una predisposición genética que explica la propensión humana hacia los procesos de reciprocidad por encima de sus facultades intelectuales. Ello le permite declarar que hay una relación entre las condiciones biológicas del individuo y las motivaciones para establecer procesos de reconocimiento, lo cual indica que la tendencia de instituir relaciones subjetivas y propiciar prácticas de reconocimiento es una facultad connatural al individuo. De esta manera, "en el proceso evolutivo infantil la adquisición de la capacidad cognitiva está enlazado de manera singular con la formación de las primeras relaciones comunicativas" (Honneth, 2007, p. 63). 
Con intención de explicar la preponderancia de la acción comunicativa como fundamento de los procesos interactivos que anteceden a las funciones cognitivas del infante, Honneth (1997) hace alusión al periodo psíquico denominado revolución del noveno mes ${ }^{4}$ para señalar la relevancia de la perspectiva de una segunda persona en la superación de la conducta egocéntrica del niño, permitiendo su apertura al mundo. En este sentido, citando a Tomasello (2007), se podría decir que este momento evolutivo del bebé es de vital importancia, porque "a esta edad, los infantes comienzan a 'estar en sintonía' con la atención que los adultos dirigen a entidades externas y con la conducta que observan respecto de estas" (p. 84), lo que indica que el niño antes de atender a su capacidad perceptiva primeramente reconoce la presencia de la persona con la que interactúa inicialmente y adopta la manera en que esta concibe el entorno.

De acuerdo con lo expuesto anteriormente, cabe señalar que la explicación evolutiva del proceso de desarrollo del infante desencadena en la preeminencia ontogenética del reconocimiento frente al conocimiento, en la medida en que "el niño tiene que haberse identificado primero con la persona de referencia antes que permitir que la actitud de esta se convierta en instancia correctiva" (Honneth, 2007, p. 65). De ello se infiere que la sensibilidad, la interacción y la empatía hacia el otro, desde la génesis humana, trascienden las nociones epistémicas experimentadas por el sujeto, asumiéndose como agente activo de su existencialidad. Es por esto por lo que, según Honneth (2007), "no debemos pensar en el que actúa como sujeto epistémico, sino como un sujeto involucrado

\footnotetext{
${ }^{4}$ Cuando Tomasello (2007) habla de revolución del noveno mes se refiere al surgimiento de un conjunto de conductas triádicas en las cuales el niño, en cuanto individuo, coordina procesos de interacción con los objetos y las personas. De ese modo, se establece un sistema triangular de intercomunicación entre el yo, el otro y el objeto significativo. Es apropiado subrayar que el proceso comunicativo que se teje en esta relación triádica es una estrategia consciente utilizada por el niño para captar la atención del adulto, estableciendo con ello procesos de reconocimiento (Tomasello, 2007).
} 
existencialmente, que toma conocimiento de los estados de sensibilidad no de manera neutral, sino afectado por ellos en la relación consigo mismo" (p. 76). En tal sentido, cuando ocurre un fallo que afecta las significaciones existenciales de los sujetos, no nos encontramos frente a una deficiencia que perturbe al conocimiento, sino frente a una patología que impide la práctica de procesos genuinos de interacción, es decir, nos hallamos frente a un fallo de reconocimiento (Mulhall, 1994).

En ese orden de ideas, las falencias que pueda tener un sujeto en sus facultades cognitivas simplemente ponen en evidencia su desconocimiento de algo, su ignorancia o su limitación a la hora de asumir determinada información. No obstante, cuando se produce un error de reconocimiento, es la presencia de algo la que se encuentra mirada con desdén, con desidia o con indiferencia (Cavell, 1969). Así, la brecha que hay entre un fallo en el conocimiento y un fallo en el reconocimiento, entre lo teórico y lo práctico, consiste en que en el primero de los casos se sufre por la ausencia de información que enriquece al intelecto; en cambio, en el segundo de los casos se sufre porque la presencia de alguien resulta siendo invisibilizada o tratada con menosprecio.

\section{Honneth: una mirada de la reificación como el olvido del reconocimiento}

Si existe una preeminencia de la posición originaria del reconocimiento sobre el conocimiento, de lo precognitivo sobre lo cognitivo, entonces, según Honneth (2007), ¿̇a qué se debe la implementación de la reificación y el menosprecio como praxis fallida de la sociedad? Respecto a este interrogante, Honneth (2007) parte de la percepción lukacsiana que considera que la reificación se origina "solo cuando las formas objetivadas en la sociedad reciben funciones que ponen la esencia del hombre en conflicto con su ser, subyugando, deformando y lacerando la esencia 
humana" (Lukács, 1970, pp. 20-21). Debido a ello, según Honneth (2007), Lukács (1970) llegó a concebir la idea de que "tenemos que representarnos el proceso de reificación precisamente como aquel proceso por el cual la perspectiva participativa original es neutralizada de tal manera que acaba favoreciendo la finalidad del pensar objetivador" (Honneth, 2007, p. 86). No obstante, con Honneth (2007) se infiere que la noción de reificación de Lukács (1970), además de estar arraigada a la objetivación y al proceso de intercambio en el capitalismo, manifiesta errores categoriales que impiden realizar una reflexión pertinente que conduzcan al adecuado análisis de una etiología social de la reificación 5 .

Partiendo de lo expuesto por Lukács (1970), Honneth (2007) aclara que "si la reificación realmente coincidiera con la objetivación de nuestro pensamiento, todo proceso social que demanda una objetivación tal sería ya una manifestación del proceso de reificación” (p. 87), lo cual permite comprender que, si bien es cierto que en el proceso objetivador del intercambio (en el que siempre permanecen presente las partes) se genera la despersonalización de quienes participan de la transacción monetaria, en la reificación lo que se hace es suprimir la humanidad del otro, olvidarse de su existencialidad, invisibilizarlo o someterlo a la experiencia del menosprecio. En este sentido, Honneth presenta una nueva perspectiva de la reificación en términos de un olvido del reconocimiento, distinguiéndose de la teoría de la objetivación lukacsiana, toda vez que el olvido implica perder de vista la presencia existencial del otro, en cuanto postura ontológica previa a la de la cognición (Fleitas, 2014).

\footnotetext{
${ }^{5}$ Cuando se pretende esbozar una etiología de la reificación a la luz de Honneth, se identifica una patología mental que es ocasionada por el olvido del reconocimiento existencial. Dicho olvido surge porque el sujeto desatiende, restringe o reprime la condición connatural que lo predispone a procesos interactivos que evidencian su tendencia hacia el reconocimiento. Por ello, lejos de las categorías lukacsianas que urden las raíces de la reificación en las premisas mercantiles, Honneth (2007) propone que la reificación se origina justo cuando la concepción cognitiva y positivista del mundo aparece como algo independiente de los aspectos precognitivos y afectivos, como si la posibilidad de la cognición no quedara supeditada al reconocimiento existencial (Basaure, 2011).
} 
Así, los evidentes errores de Lukács (1970) respecto al origen de la reificación, al concebir esta patología como mera objetivación y no como el olvido del reconocimiento, obligan a Honneth (2007) a buscar posibles vías que expliquen la génesis real de la cosificación manifestada en términos de invisibilización y experiencias de menosprecio.

Frente a la necesidad de explicar el origen de la reificación en perspectiva del olvido del reconocimiento, Honneth (2007), acudiendo al análisis esbozado por Habermas (1992), intenta “decidir [...], en qué esferas sociales son necesarias funcionalmente ya la postura de reconocimiento, ya la postura objetivadora (Honneth, 2007, p. 89). De este modo, la posibilidad de la reificación, según se analiza en las acotaciones habermasianas, se abordaría desde la ruptura del ámbito comunicativo, como efecto de la consolidación del capitalismo en la estructura social. De hecho, cuando Habermas (1992) señala explícitamente que "las estructuras simbólicas del mundo de la vida quedan deformadas, esto es, quedan cosificadas bajo los imperativos de los sub-sistemas diferenciados y autonomizados a través de los medios dinero y poder" (p. 402), está considerando que lo patológico de la cosificación se ciñe al abandono de las categorías comunicativas que definen y dan sentido al mundo de la vida.

Con base en ello, Honneth (2007) percibe que, a la luz de Habermas (1992), se puede comprender la reificación como un proceso mecánico en el que la actitud desapasionada, desinteresada e indolente del individuo penetra tan radicalmente en la vida social que, incluso, los elementos simbólicos que propiciaban y dotaban de sentido a la praxis comunicativa se desvanecen ante las categorías racionalizadas y mercantiles de la sociedad capitalista (Honneth, 2007). 
No obstante, tomando distancia de Habermas (1992), Honneth (2007) resalta que el hecho de abandonar la presencia del otro, más allá de obedecer a las causales que giran en torno a la cosificación de las prácticas comunicativas cotidianas en términos de colonización del mundo de la vida $^{6}$ (Habermas, 1992, p. 546), es el resultado de la invisbilización de quien es sometido al olvido del reconocimiento, entendido como el "proceso por el cual en nuestro saber acerca de otras personas y en el conocimiento de las mismas se pierde la conciencia de en qué medida ambos se deben a la implicación y el reconocimiento previo" (Honneth, 2007, p. 91).

Afianzando lo dicho, es preciso aclarar que, si bien Honneth (2007) reconoce la preponderancia de la acción comunicativa en la praxis de la interacción, la patología social de la reificación solo se explica desde el olvido, no como un desarraigo o sustracción total del reconocimiento, sino como una disminución de la atención. Dicho en términos de Honneth (2007), "la reificación en el sentido de un "olvido del reconocimiento" significa entonces, en la ejecución del conocer, perder la atención para el hecho de que este conocimiento se deba a un reconocimiento previo" (p. 96).

Para ejemplificar la manera en que un sujeto se olvida de la presencia del otro y lo invisibiliza, Honneth (2007), en primer lugar, hace referencia a la radicalización de una postura personal: pretendiendo alcanzar un objetivo particular, el ser humano es capaz de invisibilizar a la persona que tiene enfrente, olvidando cualquier tipo de lazo afectivo que le une a este.

\footnotetext{
${ }^{6}$ La colonización del mundo de la vida es un proceso sistemático que surge por el abandono de las premisas históricas y significativas que, a través de las categorías de la interacción comunicativa, dotaban de sentido el accionar humano. Así, la racionalización impuesta por las premisas capitalistas y manifestada desde la lógica sistemática de la economía del cálculo desprende del individuo cualquier posibilidad de acción deliberada y lo encierra en un sistema rígido y acabado que, al cosificarlo, le impide asumir un papel activo en el horizonte comunicativo de la sociedad (Habermas, 1992).
} 
Ello implica que no hay intención de compartir empática y

desinteresadamente la vida del otro, sino que las condiciones teleológicas del sujeto que actúa en beneficio propio tienden a ser indolentes y egoístas, lo cual hace que los fines existenciales del otro no sean tenidos en cuenta.

En segundo lugar, Honneth (2007) señala que otra fuente del olvido, que por cierto es más bien una especie de negación o de resistencia, tiene que ver con "esquemas de pensamientos que influyen en nuestra praxis llevándonos a realizar una interpretación selectiva de los hechos sociales" (p. 97). Esta fuente de reificación se relaciona con la animadversión que se manifiesta frente a estereotipos físicos, psicológicos, sociales o culturales que no se encuentran inmersos en los parámetros de "normalidad" construidos e impuestos por las corrientes ideológicas imperantes7.

A partir de las orientaciones descritas, Honneth (2011) concluye que el olvido del reconocimiento que se manifiesta en la negación de un individuo o de un grupo social degenera en prácticas indolentes que redundan en "la capacidad de demostrar nuestro desprecio a personas presentes mediante el hecho de comportarnos frente a ella como si no figurara físicamente en el mismo espacio" (p. 166), dando lugar a procesos de invisibilización y experiencias de menosprecio que, además de someter sistemáticamente a un individuo o un grupo social a la violencia, la tortura, la desposesión de derechos y la indignidad, configuran unas condiciones sociales que inevitablemente devienen en enfermedad, muerte psíquica y muerte social.

\footnotetext{
7 Honneth (2007) se refiere aquí a las ideologías que imperan sobre una cultura tradicionalmente constituida. Sin embargo, no ahonda en este problema porque, por un lado, considera que este se desprende de toda fuente de reificación, y allí se plantea un sinnúmero de conclusiones que engloban todo el constructo teórico del tema multicultural y pluriétnico. Por otro lado, Honneth (2007) tampoco profundiza en este asunto, porque la razón de ser de su investigación no se fundamente en la manera como está determinado el ethos cultural de las comunidades minoritariamente constituidas, sino que su análisis busca identificar la manera en que los esquemas de pensamiento y ciertos perjuicios conllevan la negación, resistencia, olvido e invisibilización de quien asume la vida desde una perspectiva diferente.
} 


\section{Las formas de menosprecio: causa y fundamento de la lucha por el reconocimiento}

Para explicar detalladamente las experiencias que imposibilitan la aquiescencia social e impiden mantener la atención frente a la presencia significativa de determinado individuo o grupo social, Honneth (1997) identifica tres formas de menosprecio que exponen las consecuencias físicas y psicológicas que traen consigo los diversos tipos de maltratos que anulan la experiencia del reconocimiento.

Como instancia inicial, Honneth (1997) describe que la primera forma de menosprecio ocurre "cuando a un hombre se le retiran voluntariamente todas las posibilidades de libre disposición en su cuerpo, representan el modo elemental de una humillación personal” (p. 161). No obstante, Honneth (1997) precisa que el maltrato físico que se relaciona con la violencia y la tortura, más allá del dolor corporal, está asociado con la actitud de indefensión frente a la voluntad del otro. Esto implica que el menosprecio físico, al constituirse en una forma de irrespeto sobre el cuerpo de quien sufre la tortura, hace que se lesione la autoconfianza y se genere un sentimiento de vergüenza social. Así, "la lograda integración de las cualidades de comportamiento corporales o anímicas se quebrantan desde fuera y con ello se destruyen las formas elementales de la autorreferencia práctica, la confianza de sí mismo" (Honneth, 1997, p. 162). En ese sentido, la severidad de la fuerza física que un sujeto imprime sobre su semejante anula la posibilidad de que este pueda sentirse seguro de sí dentro de la esfera social, lo que indica que la violencia, más allá de la afección somática y psíquica, "produce en quien la padece una ofensa, un sentimiento negativo que muchas veces conduce a la muerte" (Tovar, 2004, p. 101).

La segunda forma de menosprecio que identifica Honneth (1997) tiene que ver con la desposesión de derechos, la cual "no consiste solamente en la 
limitación violenta de la autonomía personal, sino en su conexión con el sentimiento de no poseer el estatus de interacción moralmente igual y plenamente valioso" (p. 163). Aquí al individuo se le restringe la posibilidad de emitir juicios morales, lo que implica la pérdida del respeto de sí mismo, toda vez que no puede establecer una relación interpersonal enmarcada dentro de la legitimidad social. De ello se infiere que la herida moral, "que resulta de no reconocerle, en el interior de su comunidad social, la capacidad de responsabilidad moral propia de una persona con plenitud de derechos" (Fernández y Vasco, 2012, p. 470), hace que las relaciones humanas adolezcan de un aparato normativo incluyente que propicie un escenario de respeto mutuo.

La tercera forma de menosprecio, según Honneth (1997), está relacionada con las categorías de injuria y deshonra; en esta se somete a alguien a la degradación, porque sus aspiraciones personales o culturales no son tenidas en cuenta en el núcleo social imperante. En ese sentido, Honneth (1997) señala que el individuo no puede

referirse a su modo de vivir como algo a lo que, dentro de la comunidad, se le atribuye una significación positiva, con ello, para el singular con la experiencia de tal desvalorización se conjuga una pérdida en la autoestima personal y, por consiguiente, de la oportunidad de poder entenderse como un ente estimado en sus capacidades y cualidades características. (p. 164)

La desvalorización descrita en esta última forma de menosprecio conlleva observar que la desestimación de un individuo por parte del círculo social dominante mutila las motivaciones internas que permiten la autopercepción positiva de sí mismo, e impiden la materialización de las categorías culturales que construyen su horizonte significativo. 
Finalizado el análisis de las tres formas de menosprecio, se puede señalar, de manera sucinta, que estas prácticas se desarrollan "por la desvalorización social de ciertos modos de vida individuales o colectivos, dependiente de patrones culturales que determinan el valor y sentido de las actividades y contribuciones individuales o grupales" (Fascioli, 2011, p. 57). Esto denota que la posibilidad de la valoración social no se configura como algo circunscrito dentro del carácter de obligatoriedad, sino que se encuentra determinado por la posición de privilegio que ostenta determinado individuo o grupo social. Por ello, las formas de menosprecio señaladas por Honneth (1997) pueden asumirse como un problema de tipo moral, toda vez que, al no existir patrones universales que condicionen las relaciones intersubjetivas, se suscitan sociedades proclives a experimentar vínculos sociales desiguales, cosificadores y excluyentes.

\section{Honneth y Hegel: una mirada a la lucha por el reconocimiento como causa del fenómeno moral}

Habiendo configurado los presupuestos conceptuales que describen el problema del reconocimiento como categoría clave en la estructura de la modernidad, se pudo observar que la pregunta por la resignificación humana no aparece como un evento posterior a la cognición, sino como una condición de posibilidad de esta. Esto permite comprender el surgimiento de las patologías sociales a partir de la desatención del ser humano frente a la presencia del otro, lo que genera expresiones de menosprecio que dañan física y psíquicamente a quien ha sufrido maltrato, deshonra e injuria. Con la descripción de estas experiencias que transgreden el fenómeno moral, Honneth (1997) se encuentra ante la necesidad de establecer criterios conceptuales que permitan abordar la categoría del reconocimiento a partir de las luchas que históricamente se 
fraguaron para preservar el autorrespeto, la autoconfianza y la autoestima, tomando como camino los diferentes estadios que atraviesa el sujeto para alcanzar dicho reconocimiento.

Si se entiende el reconocimiento como la vía moral para contravenir las distintas formas de menosprecio, resulta necesario tener presente que la materialización de la resignificación humana solo es posible desde un proceso de lucha motivada por el desarraigo de la humillación social. Movido por este principio, Honneth (1997) realiza un rastreo histórico para determinar la incipiente significación de las luchas sociales en los albores de la modernidad, como mecanismo de carácter precontractual que responde a la necesidad de la autoconservación, la preservación de la identidad física y la búsqueda incesante del bienestar futuro. Sin embargo, Honneth (1997) analiza que este proceso, en el que inicialmente Hobbes y Maquiavelo "hacen de la lucha de los sujetos por la autoconservación el punto de referencia de su análisis teórico" (p. 19), debe asumirse, siguiendo a Hegel (1968), no en términos de una disputa por la supervivencia, sino desde la perspectiva social donde las confrontaciones intersubjetivas entre los individuos se enfocan a partir de la importancia de ser concebido por el otro como presencia.

Ahondando sobre lo anterior, se puede precisar que las luchas por la autoconservación rastreadas por Honneth (1997) le permiten develar que, desde la lógica de la filosofía social arraigada en el contexto moderno, se observa al individuo como estructura atómica poco dispuesto para los procesos de interacción, lo que impide fraguar una teoría filosófico-política que ponga en escena las posibilidades del reconocimiento intersubjetivo desde un proceso de lucha.

Frente a la disyuntiva del atomismo social y los procesos de lucha por el reconocimiento, Honneth (1997) considera que debe desarrollarse un 
conjunto de categorías que puedan "reemplazar los conceptos fundamentales atomísticos, por categorías que se moldeen a partir de la conexión social” (p. 24), permitiendo así el establecimiento de los lazos éticos entre individuos. Así, suprimida la concepción individualista del sujeto, se consolida la construcción de lo social a partir de la comunicación ética, permitiendo "la transición de esa situación de 'eticidad natural' a la forma de organización de una sociedad que de antemano había tematizado como una relación de totalidad ética" (Honneth, 1997, p. 25).

Al dar el paso de la eticidad natural a procesos de conexión social, Honneth (1997) se vale de los aportes de Hegel (1968) para abordar la manera en que se tejen las experiencias de intersubjetividad. Para ello, tomando la noción de la filosofía de la conciencia de Hegel (1968), describe el proceso dialéctico de realización del espíritu, mostrando la manera en que "el espíritu es llevado a presentación, primero a su constitución interna como tal, luego a su enajenación a la objetividad de la naturaleza y finalmente en el regreso a la esfera de la propia subjetividad" (Honneth, 1997, p. 46). Con ello, recrea la secuencia metódica y escalonada en que la conciencia identifica tres momentos de la realidad: "primero, la relación del sujeto individual consigo mismo, luego, las relaciones institucionales de los sujetos entre sí y, finalmente, las relaciones reflexivas de los sujetos socializados con el mundo" (Honneth, 1997, p. 48).

Esta apreciación tripartita de la realidad permite divisar que, en la filosofía de la conciencia, el espíritu, al hacerse conciencia de sí para sí y conciencia de sí para otros, fundamenta su accionar no en sus capacidades cognitivas, sino en la dimensión práctico-mundana que aflora a partir de la formación de la voluntad, en cuanto "formas de la autoexperiencia que resultan de un proyecto orientado a la realización práctica, 'objetiva', de las propias intenciones" (Honneth, 1997, p. 49). 
A propósito de lo enunciado hasta aquí, es preciso señalar que la realización de las propias intenciones está supeditada a establecer procesos de interacción que permitan la confirmación de los ideales propios en la conciencia del otro y, a su vez, la confirmación de los ideales del otro en mí. Esto indica lo siguiente:

Si yo no reconozco al otro en la interacción como un determinado tipo de persona, tampoco puedo verme reconocido como tal tipo de persona en mis reacciones, porque a él precisamente debo concederle las cualidades y facultades en que quiero ser confirmado por él. (Honneth, 1997, p. 53)

Para esbozar los procesos de conformación social que constituyen la fenomenología de las posibilidades de interacción, Honneth (1997) toma de Hegel (1968) la estructura sistemática del reconocimiento sostenida en la idea de la familia, la sociedad civil y el Estado. En el caso del primer estadio, la familia se constituye en el momento inicial en que el individuo experimenta la descentralización de su propio ser y conjuga experiencias significativas con sus congéneres. A propósito de ello, Hegel (1968) considera lo siguiente:

La familia, como sustancialidad inmediata del Espíritu, es determinada por el Amor a su unidad afectiva; de suerte que su condición es poseer la autoconciencia de la propia individualidad en esa unidad, como esencialidad en sí y por sí, por ser en ella no como persona por sí, sino como miembro. (p. 157)

El hecho de ser un miembro de la unidad afectiva que se reviste en el amor familiar indica que la individualidad del ser humano está supeditada a la compenetración filial de quienes integran el núcleo del hogar. Esto conlleva que la familia, según lo asume Hegel (1968), se conciba como una forma de eticidad en su fase más natural y primitiva, fundamentada por el amor y la unidad entre sus miembros, lo que permite inferir que en esta 
esfera no se hace necesaria la conformación de un pacto social manifestado en el derecho, porque la compenetración natural entre los miembros de la familia hace que se perciban como un momento específico del todo y no como sujetos individuales que necesitan de un aparato jurídico que les garantice su integridad. Sin embargo, resulta importante señalar que en esta fase el sujeto, haciendo uso de su voluntad, empieza a configurarse a partir del anhelo y la necesidad de ser amado por el otro, haciendo de la constitución del amor el presupuesto necesario para los procesos genuinos de reconocimiento.

En tal sentido, la manifestación del amor y la confianza que devienen en reconocimiento recíproco se constituyen en elementos legitimadores de la formación y expresión de la voluntad política, toda vez que el reconocimiento del ser amado se convierte en la huella psíquica interna que permite el acceso a la comunidad ética.

Así, el contorno limitado en el que se cimientan las relaciones afectivas, como ocurre en la familia, no le permite al sujeto conocer la condición de la vida social y las funciones que deben asumir dentro de ella (Honneth, 1997), puesto que la interacción social termina dependiendo exclusivamente de la relación filial que existe entre los miembros de un delimitado círculo social, sin procurar que dichas relaciones se encuentren enmarcadas dentro de un sistema jurídico positivo que le otorgue a la dinámica de la interacción el carácter de obligatoriedad moral. No obstante, la familia, al constituirse en una especie primaria de la construcción de los patrones de reconocimiento, funge como puerta de acceso al proceso de interacción.

Dicho de otro modo:

Aquello que podemos englobar genéricamente bajo la idea del amor, afecto o empatía hacia el prójimo es lo que constituye el sustrato y el

Cuadernos de Filosofía Latinoamericana ISSN: 0120-8462 | e-ISSN: 2500-5375 | DOI: https://doi.org/10.15332/25005375 
elemento sustancial a partir del cual desarrollar el resto de actitudes y experiencias de reconocimiento, lo cual nos revela, precisamente, la importancia axial de la dimensión afectiva del ser humano. (Gil, 2015, p. 72)

Luego de analizar la estructura familiar y la relación simbiótica ${ }^{8}$ entre sus miembros, es importante señalar que las condiciones afectivas que se patentizan en la familia tienden a particularizarse debido al ideal de vida de cada uno de sus miembros. En ese sentido, "los momentos ligados en la unidad de la familia como idea ética, tal como esta existe en su concepto, necesitan ser emancipados de él, como una realidad independiente, es decir, en la fase de la diferencia” (Hegel, 1968, p. 171).

Cabe aclarar que en Hegel (1968) esta diferenciación que permite la particularización de los miembros de la familia, lejos de afianzar lo singular como factor determinante que hace desaparecer la eticidad, se vale de lo particular como elemento de la universalidad que permite la construcción de contextos en el que se teje el horizonte ético de las relaciones humanas.

En ese orden de ideas, podría decirse que "la moral individual, que busca la universalidad, solo puede realizarse quedando encarnada en instituciones y costumbres porque éstas son la vida misma del Estado ético en los individuos" (Dri, 1991, p. 33). En esta medida, la reciprocidad entre particulares propicia la institucionalidad universal con el fin de salvaguardar los principios que garantizan la satisfacción y la valoración mutua. En tal condición, la persona particular está esencialmente en relación con otra particularidad, de manera tal que solo se hace valer y se

\footnotetext{
${ }^{8}$ La importancia de la simbiosis entre el hijo y la madre se constituye, según Honneth (1997), en la condición para que el sujeto en formación cultive su autonomía y participe de procesos de conexión con sus congéneres. En ese sentido, la relación simbiótica, lejos de coartar las posibilidades autónomas de los sujetos, construye su independencia, ayudando a definir los ideales de su propia vida (Aparicio, 2016).
} 
satisface por medio de la otra y, a la vez, solo por la mediación de la forma de la universalidad que es el otro principio (Hegel, 1968).

Esta perspectiva histórica, en la que se funden los individuos independientes en derredor de la satisfacción de necesidades, hace que ocurra la construcción contractual de premisas universales que se manifiestan en el respeto de los derechos y las obligaciones y, a su vez, permite, desde la obligatoriedad jurídica, que se garanticen los intereses y propiedades comunes, dando paso a lo que Hegel (1968) denomina la transición de la familia a la sociedad civil9.

Así, la sociedad civil, al constituirse a partir del conjunto de lo particular dentro de lo universal y sustentarse en un orden exterior y jurídico contractual en el que cada singularidad pueda expresar su independencia sin dañar o ser dañado por otro, se constituye en una fase vital de los procesos de reconocimiento, puesto que garantiza la presencia del otro como sujeto de derechos.

Ello le permite a Honneth (1997) inferir que "sin la imposición de las obligaciones que resulten del consentimiento del contrato, el sujeto de reglas de reconocimiento, a los que debe su estatuto de persona jurídica, resultaría dañado" (p. 71). Esto conlleva que el reconocimiento, como ocurre en la sociedad civil, se constituya en el objeto de la producción del derecho, puesto que, al regularse universalmente la relación del comportamiento de unas personas con otras, se afirman directrices que le permiten querer lo universal, formarse como ciudadano y consolidarse como miembro de una sociedad política. Ello indica que "solo en la sociedad civil el hombre realiza su educación en lo universal, se prepara

\footnotetext{
${ }^{9}$ De la estructura de la familia se forman sujetos independientes que, al hacer uso de su libertad, se constituyen en una realidad autónoma que, pese a las condiciones diferentes de la estructura de su identidad, asume la universalidad como la posibilidad de desarrollar sus particularidades (Hegel, 1968).
} 
para convertirse en ciudadano y para querer lo universal como tal" (Hyppolite, 1970, p. 119).

Dada la importancia de la experiencia del espíritu en las progresivas relaciones de amor, y teniendo en cuenta la relevancia de la realización de las relaciones conflictivas que descansan en el derecho y la sociedad civil, en Hegel (1968) se percibe que, más allá de los estadios antes definidos, "la pretención del sujeto de ser respatado en la particularidad de su propia vida, no se satisface en la esfera del derecho, sino en còmo conseguir su confirmación en la esfera del espíritu del pueblo, representado y sostenido por el Estado" (Honnteh, 1997, p. 74).

Desde lo explicado previamente, resulta importante decir que la trascendencia del Estado radica en que se construye desde la individualidad elevada a la universalidad, propiciando espacios sociales “donde la libertad alcanza la plenitud de sus derechos, así como este fin último tiene el más alto derecho frente a los individuos, cuyo deber supremo es el de ser miembros del Estado" (Hegel, 1968, p. 212). En esta perspectiva, el Estado se establece como el fin último en donde cada miembro de la comunidad política encuentra sentido como individuo, siempre y cuando sustente sus relaciones recíprocas, sus costumbres culturales y sus diversos procesos de interacción, según las exigencias de los parámetros del Estado. Esto permite inferir que, dentro del dictamen estatal, la conciencia de sí del ciudadano, amparado en sus relaciones fraternas y regido por practicas jurídicas de la sociedad civil, establece procesos genuinos de reconocimiento que promulgan la integración social de una comunidad política. 


\section{Las esferas del reconocimiento en la teoría de AxI Honneth}

Luego de abordar la filosofía de la conciencia y el análisis del progreso del espíritu que se manifiesta desde la institucionalidad constituida a partir de los estadios de reconocimiento explicitados por Hegel (1968), resulta relevante señalar que estos momentos del espíritu le sirven de base a Honneth (1997) para fundamentar la división tripartita de su teoría del reconocimiento a partir de las nociones de amor, derechos y solidaridad.

Para describir la primera fase del reconocimiento correspondiente al amor, Honneth (1997), tomando la concepción psicológica de Donald Winnicott (1979), explica la manera en que se construye una postura positiva de la propia subjetividad desde la forma en que se entretejen los procesos de dependencia e independencia en el que se circunscribe la relación simbiótica entre el hijo y la madre, lo que permite develar que "la salud psíquica del individuo depende de una relación lúdico-exploratoria con la propia vida pulsional" (Honneth, 2007, p. 104). Así, como quiera que la vida pulsional del sujeto $-\mathrm{y}$, por ende, la posibilidad del autorreconocimiento- está arraigada a relaciones parental-maternales, es posible afirmar desde Winnicott (1979) que la salud mental del ser humano, junto a su desarrollo emocional de toda su vida, tiene como fundamento la relación simbiótica que existe con la madre y con el medio circundante.

De lo anterior, Honneth (1997) comprende que el sentido de la vida del infante está sujeto a las atenciones que la madre tenga con este, dando por supuesto que los cuidados maternales "no se añaden como algo secundario al comportamiento infantil, sino que se funde con él de tal manera que es plausible aceptar para el comienzo de toda vida humana una fase de subjetividad inferenciada" (p. 121). Esto indica la importancia de la persona de referencia, no para socavar los procesos de identidad del 
individuo, sino para aseverar que dicha identidad se construye desde la identificación con el otro. En términos de Winnicott (1993), la simbiosis entre madre e hijo es absolutamente necesaria, porque "sin ese yo auxiliar, el yo del infante carece de forma, es débil, se lo fragmenta con facilidad, y es incapaz de crecer siguiendo los lineamientos del proceso de la maduración" (p. 307).

No obstante, Honneth (1997), partiendo de esta dependencia de la subjetividad primaria esbozada por Winnicott (1993), se pregunta: “¿Cómo está constituido el proceso de interacción por el que la madre e hijo pueden desprenderse de tal situación de ser-uno indiferenciado, de modo que al final del proceso aprendan a amarse y aceptarse como personas independientes?” (Honneth, 1997, p. 122).

Según Winnicott (1993), la connotación simbiótica de la interacción madre-hijo, lejos de coartar los procesos de independencia subjetiva, muestra la forma en que la figura materna propicia el ambiente adecuado para que el precoz emprenda el proceso de maduración. En tal sentido, explica Winnicott (1993), el impulso humano hacia la integración se produce por las tendencias heredadas de los progenitores y el ambiente facilitador que construyen alrededor del infante, con el fin de dar cuenta del proceso de crecimiento y maduración del precoz.

Identificada la importancia de la conexión simbiótica de la persona de referencia con el infante y la importancia del contexto en su crecimiento, resulta relevante decir que quien cumple el rol de acompañante significativo, según señala Jessica Benjamin (1996), "no es sencillamente un objeto de las demandas de su hijo; es, en realidad, otro sujeto, cuyo centro independiente debe estar fuera del bebé para asegurarle el reconocimiento que él busca" (p. 37). Esto significa que la persona de referencia, al estar compenetrada con el niño, se sitúa en la vida del 
infante como garante de sus procesos de reconocimiento. Ello denota que la presencia imitativa le permite al niño descubrir la condición connatural de sus posibilidades de interacción, ya que la figura de la madre, al constituirse en relación simbiótica con su hijo, hace que el impúber se inserte en el mundo social, estableciendo tejidos comunicativos enmarcados en la confianza, el reconocimiento y la reciprocidad. Más allá de la importancia de lo anotado hasta aquí, resulta necesario precisar que, pese a que en el inicio de la relación madre-hijo existe una profunda compenetración manifestada en la sincronización, cohesión y armonía que evidencian la gran carga afectiva que circunda entre las partes (Abello y Liberman, 2011, p. 83), los procesos de maduración del niño le permiten asumir la realidad y la relación con sus congéneres desde su propia perspectiva, instaurando, a partir del desprendimiento doloroso de la madre, procesos de independencia que desencadenan en el desarrollo de su propia identidad.

Cabe señalar que la separación de la madre con el fin de luchar por la independencia de su hijo despierta una tendencia agresiva en el impúber, toda vez que siente mermada su omnipotencia; no obstante, si la madre es capaz de soportar los ataques del hijo sin reducir el amor que siente por él, este "puede desarrollar, a la sombra de su seguridad intersubjetiva, confianza en cuanto a la realización social de sus propias pretensiones de necesidad; por el cauce psíquico así abierto se logra en él generalmente una elemental 'capacidad de ser solo"'(Honneth, 1997, p. 128).

Cuando el infante logra sin angustia ser solo consigo, se encuentra preparado para los procesos de interacción porque puede establecer empatía con el otro. De hecho, Winnicott (1975) considera, de una forma u otra, que poder estar solos se constituye en la base fundamental de la amistad. Es decir, el amor a sí mismo permite las posibilidades del 
reconocimiento del otro. Respecto a ello, Honneth (1997) concluye que "a partir de los análisis de Winnicott acerca del temprano proceso de maduración, estamos en disposición de aplicar las conclusiones teoréticas a la estructura comunicativa, que hace del amor una relación específica de reconocimiento recíproco" (p. 129).

El reconocimiento recíproco y fraterno que se gesta desde la vida temprana del individuo le imprime sentido y seguridad a su existencia, permitiéndole desarrollarse en comunidad. De hecho, Honneth (1997) señala que "solo aquella conexión simbiótica, que surge por la querida y recíproca delimitación, crea la medida de la autoconfianza individual que es la base imprescindible para la participación autónoma de la vida pública" (p. 133).

Cuando la autoconfianza que emana de la simbiosis entre madre e hijo deviene en el desarrollo de la vida pública del individuo, se configura el derecho como fase posterior que describe las obligaciones normativas que se deben tener en cuenta para garantizar la integridad de los sujetos sociales (Honneth, 1997). En este contexto de la interacción, el Estado se distingue como el escenario público donde la persona, revestida de deberes y derechos, merece ser reconocida por otro, puesto que "su conciencia de sí, natural, se somete a una generalidad, a la voluntad de sí para sí, a la ley, por consiguiente se porta frente a los otros en una forma de validez general, los reconoce por lo que él mismo quiere valer en tanto que libre y persona" (Honneth, 1997, p. 133).

El hecho de que la conciencia de sí haga uso de su voluntad para dirigirse hacia patrones y preceptos de interés común que garanticen el respeto mutuo implica que los intereses generalizables de quienes participan en el contexto social están amparados en un sistema de derechos que permite el desarrollo de relaciones intersubjetivas en las que cada individuo, 
indistintamente de su visión de vida o de su contorno sociocultural, goza de una importancia superlativa (Habermas, 1989). En este orden de ideas, el derecho se constituye en la esfera del reconocimiento de carácter universal, porque "en ella se expresan los derechos universales -en sentido kantiano- donde los seres humanos se reconocen como fuente de deberes y derechos independientemente de toda caracterización de orden social, económica o cultural” (Tello, 2011, pp. 47-48).

De acuerdo con lo dicho, cabe señalar que cuando el derecho trasciende los sentimientos, la simpatía o las inclinaciones individuales, no propugna una retracción de la función autónoma y las concepciones específicas del sujeto, sino que establece procesos de reconocimiento fundamentado en la responsabilidad moral. Ello le permite a Honneth (1997) afirmar lo siguiente:

El reconocimiento jurídico se escalona todavía gradualmente conforme a la ocasional valoración que goza el singular en tanto que portador de función; pero se desprende de esa conexión a consecuencia del proceso histórico, que somete las relaciones de derecho a las exigencias de una moral posconvencional. (Honneth, 1997, p. 136)

Tal exigencia moral, que salvaguarda la función del singular, implica que se establezcan relaciones de derecho en el sentido jurídico, sin restar importancia a los procesos de valoración subjetiva. Esto permite establecer formas de respeto que se manifiestan por derecho y por comunidad de valor (Parada y Castellanos, 2015, p. 66).

Frente a esta concepción del derecho, Honneth (1997) toma los postulados de Ihering (1905) para señalar lo siguiente:

En el reconocimiento jurídico [...] se expresa que todo sujeto humano, sin diferencia alguna, debe valer como "un fin en sí mismo" mientras que "el respeto social" pone de relieve el valor de un individuo, en la medida 
en que se puede medir con criterios de relevancia social. (Honneth, 1997, p. 137)

De este modo, cuando se establece el reconocimiento jurídico como fundamento de la interacción social, se está exaltando la consagración universal de principios y libertades que impiden que los sujetos sean irrespetados o percibidos como instrumentos. Del mismo modo, cuando se instauran procesos de valoración social, se tienen presente criterios comunitarios que permiten identificar y respetar el contenido significativo de determinada práctica individual.

Esta división de la connotación del respeto deviene en una lucha por el reconocimiento, en la medida en que el respeto que se da en ambas circunstancias se encuentra determinado por las capacidades de los sujetos que aspiran a consolidar su significación personal en la esfera social. Así, cuando Honneth (1997) explicita esta dualidad en el proceso de la praxis jurídica, señala que en el primer de los casos se pretende instaurar una cualidad general que se implante desde el concepto de persona y, en el segundo caso, se examina la manera en que las cualidades particulares se han de manifestar socialmente buscando salvaguardar el respeto por la diferencia.

Cabe decir que, para Honneth (1997), estas dos circunstancias de la conciencia confluyen cuando los sujetos, al respetarse recíprocamente, deciden "proteger y posibilitar el ejercicio de aquella capacidad universal que caracteriza a los hombres como persona" (p. 139). Así, bajo esta premisa, la lucha por el reconocimiento funciona como una forma de presión respecto al incremento de las cualidades generales a las que se somete una persona moralmente responsable, buscando construir nuevos presupuestos normativos que den cuenta de la constitución de la voluntad racional (Honneth, 1997). 
Con el análisis del amor y el derecho como presupuestos teóricos que defienden la posibilidad del reconocimiento, Honneth (1997) explica cómo, desde estas categorías, el sujeto alcanza la confianza de sí y el respeto de sí, por lo que señala lo siguiente:

Como el caso del amor, el niño, por la experiencia prolongada de la dedicación maternal conquista la confianza de dar a conocer sin trabas sus necesidades, igual que el sujeto adulto, por la experiencia del reconocimiento jurídico, conquista la posibilidad de concebir su obrar como una exteriorización, respetada por todos, de la propia autonomía. (p. 145)

Ello indica que el amor y el derecho se constituyen en fases fundamentales que atraviesa el sujeto para descubrirse a partir de sus implicaciones sociales, en términos de autoconfianza y autorrespeto.

Como complemento de lo reseñado, Honneth (1997) resalta que las fases del amor y el derecho deben complementarse con la implementación de prácticas valorativas, ya que "para poder conseguir una ininterrumpida autorrealización, los sujetos humanos necesitan, más allá de la educación afectiva y el reconocimiento jurídico, una valoración social que les permite referirse positivamente a sus cualidades y facultades concretas" (p. 148). Así, la valoración de los caracteres y las potencialidades de cada individuo introducen la intención honnethiana de encontrar en la solidaridad la facultad complementaria que, junto con el amor y el derecho, establecen los criterios de la posibilidad del reconocimiento intersubjetivo.

La necesidad de establecer relaciones de implicación que se tejan desde la solidaridad conduce a realizar un análisis de los arquetipos culturales que se amparan en las nociones del honor y de privilegios. Estos, fraguados en el contexto sociofeudal premoderno, indican que "la consideración de una persona se mide por el concepto de honor social" (Honneth, 1997, p. 150), 
mostrando una especie de estratificación de los vínculos sociales en la que los privilegiados sustentan sus posibilidades de reconocimiento, reafirmando la imagen despreciable que se tiene de los desfavorecidos.

En ese sentido, para Pitt-Rivers (1979), por ejemplo, el honor se configura cuando la imagen valorativa que se tenga de sí mismo, lejos de ser recusable, encaja con el estereotipo que la sociedad exige para que determinado individuo sea considerado importante. De acuerdo con ello,

un honor, un hombre de honor o el epíteto honorable pueden aplicarse apropiadamente en cualquier sociedad, ya que son términos valorativos [...] El concepto de honor es más que un medio de expresar aprobación o desaprobación. Posee una estructura general que se ve en las instituciones y en las valoraciones habituales propias de una cultura dada. (Rivers, 1979, p. 17)

De este modo, el prestigio social obedece a un proceso de monopolización en el que determinada cultura construye una estructura institucional que excluye de todo privilegio social a aquellos que no ostentan una posición de influjo (Honneth, 1997). Ello, según Weber (1964), conduce hacia el cierre de las relaciones sociales, puesto que procurar una alta calidad de vida que se limite al prestigio, el honor y la ganancia impide que se establezcan auténticos procesos de interacción, toda vez que quienes, por razones culturales, políticas o económicas, no participan de una condición favorecida son rezagados e invisibilizados socialmente.

Este contorno en donde el proceso de reconocimiento se encuentra supeditado a la posición de privilegio que tenga un determinado grupo social es un envión anímico para que las comunidades en condiciones de desprecio emprendan un proceso de lucha, buscando socavar las bases de una sociedad que condiciona el valor de la persona a la estratificación o la 
preeminencia social que le corresponde. En ese sentido, Honneth (1997) señala lo siguiente:

La lucha que la burguesía, en los umbrales de la modernidad, comenzó a librar contra las representaciones feudales de los nobles, no fue solo el intento colectivo de introducir nuevos principios, sino también la iniciación de un debate en torno al estatus de tales principios de valor general. (Honneth, 1997, p. 153)

Este debate, abanderado por la premisa de salvaguardar la dignidad e integridad de cada persona, permite la consolidación de derechos individuales que, erradicando las relaciones sociales basadas en la privatización del honor, garanticen el valor y la reputación social de cada sujeto. De este modo, la lucha asumida por la burguesía deviene en individualización, porque "ya no son las cualidades colectivas, sino las capacidades histórico-vitalmente desarrolladas del singular, lo que comienza a orientar la valoración social” (Honneth, 1997, p. 154).

Cabe decir que, según Honneth (1997), los esfuerzos de la burguesía por ponderar el derecho moderno ${ }^{10}$ no puede quedarse en el atomismo social que desestima el horizonte cultural y comunitario, sino que, sin desatender la valoración subjetiva, debe garantizarse "un tipo de relación de interacción en el que los sujetos recíprocamente participan en sus vidas diferenciables, porque se valoran entre sí en forma simétrica” (p. 157). En ese orden de ideas, la valoración del singular, manifestado en el desarrollo de la autoestima, trasciende hacia la apreciación de las capacidades de los congéneres, toda vez que al "considerarse recíprocamente a la luz de los

\footnotetext{
${ }^{10}$ Para la teoría crítica, la burguesía se constituye en un instrumento de dominio que fundamenta el derecho moderno en las pretensiones de propiedad, lo cual indica que las revoluciones históricas que marcaron el curso de los tiempos modernos acentuaron las condiciones monetarias de quienes detentan el poder (Horkheimer, 2006). De este modo, la instauración de la industria cultural, la implementación del consumo de masas y la construcción de un orden social que se fundamente en el individualismo exigen que se vislumbre un horizonte normativo que resuelva la tensión entre la dominación y la emancipación (Sembler, 2010).
} 
valores que hace aparecer las capacidades y cualidades de cualquier otro como significativas para la praxis común" (Honneth, 1997, p. 158), de una forma u otra, establecen relaciones de empatía en la que, indistintamente de la cercanía afectiva con determinado sujeto, se estiman las propiedades individuales de quienes participan en los procesos de interacción para construir el horizonte social.

En esta perspectiva, la relación de solidaridad halla sentido cuando el singular es interpelado por la particularidad individual de sus congéneres, "incrementando nuestra sensibilidad a los detalles particulares del dolor y de la humillación de seres humanos distintos, desconocidos para nosotros" (Rorty, 2001, p. 18). Esto indica que la praxis de la solidaridad no implica simplemente tener presente el sufrimiento del otro o percatarse de sus desgracias, sino que obedece al involucramiento afectivo que se tiene frente a una experiencia ajena de desdicha y dolor.

La preocupación por las vivencias del otro, sobre todo si se trata de experiencias de sufrimiento, permite construir sociedades solidarias que centran sus posibilidades de realización desde la instauración de un horizonte común fundamentado en la praxis de la empatía. En ese sentido, "solo en la medida en que yo activamente me preocupo de que el otro pueda desarrollar cualidades que me son extrañas, pueden realizarse los objetivos que nos son comunes" (Honneth, 19997, p. 159). Así, la valoración social que se circunscribe en la praxis solidaria evidencia que la conexión íntima, desinteresada y fraterna entre los sujetos, además de impedir que se invisibilicen las situaciones de agravio al que es sometido determinada persona, permite la instauración de metas comunes que buscan salvaguardar la dignidad de todos y cada uno de los miembros de la sociedad. 


\section{Conclusión}

De acuerdo con lo señalado en el transcurso de esta reflexión, se puede concluir que, comprendido el problema de la reificación social, no desde categorías racionales cognitivas sino a partir de connotaciones ateoréticas que definen la praxis humana, el olvido sufrido se constituye en la experiencia de menosprecio que socava el sentido de la existencia. Ello se explica porque, al desatender la presencia del otro como un sujeto que espera ser reconocido, la pérdida de la propia confianza, la ausencia del autorrespeto y el sometimiento a la indignidad hacen que la vida humana se desarrolle desde una dinámica violenta, con ausencia de derechos y carente de experiencias de solidaridad.

Esta situación en la que se describen experiencias patológicas que manifiestan la depreciación del sentido de lo humano se constituye en la motivación fundamental para la implementación de un horizonte normativo que busque salvaguardar la moralidad. En ese sentido, el menosprecio social se constituye en la causa de una lucha sistemática que busca la materialización de experiencias de reconocimiento fundamentadas en el amor, el derecho y la solidaridad. No obstante, la inclinación hacia la instauración de principios normativos exige que las experiencias sociales se fundamenten desde procesos de eticidad en los que las condiciones intersubjetivas permitan la autorrealización individual, a partir de principios universales que salvaguarden la confianza, el respeto y la autoestima de cada uno de los actores del proceso de interacción. De esta manera, la descripción del fenómeno moral y las motivaciones sociales que exigen su promulgación evidencian que el menosprecio social necesariamente conduce a la implementación de la eticidad. 


\section{Referencias}

Abello, A. y Liberman, A. (2011). Una introducción a la obra de D. W. Winnicott. Contribuciones al pensamiento relacional. (A. Painceira, Trad.). Ágora Relacional.

Aparicio, M. (2016). El cuidado en la teoría del reconocimiento de Honneth. Repercusiones en la persona con diversidad funcional. Oxímora. Revista Internacional de Ética y Política, 8, 36-52.

Basaure, M. (2011). Reificación y crítica de las patologías sociales en el marco del proyecto de teoría crítica de Axel Honneth. Enrahonar, 46, 75-91.

Benjamin, J. (1996). Los lazos de Amor. Psicoanálisis, feminismo y el problema de la dominación (J. Piatigorsky, Trad.). Paidós. (Obra original publicada en 1988).

Cavell, S. (1969). Must we Mean What We Say? Cambridge University Press.

Chuca, A. (2011). El reconocimiento como definición de lo humano en Axel Honneth. IX Jornadas de Sociología. Facultad de Ciencias Sociales, Universidad de Buenos Aires.

Escudero, J. (2016). Guía de lectura de 'ser y tiempo', de Martín Heidegger. Herder.

Dri, R. (1991). Revolución burguesa y nueva racionalidad. Sociedad burguesa y razón en el joven Hegel. (J. Guiffra Trad.). Biblos.

Fascioli, A. (2011). Justicia social en clave de capacidades y reconocimiento. Areté. Revista de Filosofía, 23(1), 53-77.

Fernández, A. y Vasco, E. (2012). Dinámicas del reconocimiento en las narraciones de jóvenes con discapacidades. Revista Latinoamericana de Ciencias Sociales, Niñez y Juventud, 1o(1), 467-479. http://www.scielo.org.co/pdf/rlcs/v10n1/v10n1a30.pdf

Fleitas, M. (2014). La reificación como un olvido del reconocimiento. Apuntes para una revisión de la idea de reificación de Axel Honneth. Andamios, 11(26), 253-275.

Gil, J. (2015). El reconocimiento afectivo como contenido moral. Feuerbach en diálogo: Fichte, Hegel, Honneth. Tópicos, Revista de Filosofía, 49, 53-79.

Habermas, J. (1989). El discurso filosófico de la modernidad (M. Jiménez, Trad.). Taurus. (Obra original publicada en 1985).

Habermas, J. (1992). Teoría de la acción comunicativa, II: Crítica de la razón funcionalista (M. Jiménez, Trad.). Taurus. (Obra original publicada en 1987).

Cuadernos de Filosofía Latinoamericana

ISSN: 0120-8462 | e-ISSN: 2500-5375 | DOI: https://doi.org/10.15332/25005375

Vol. 42 N.o 125 | julio-diciembre de 2021 
Heidegger, M. (1997). Ser y tiempo (J. Rivera, Trad.). Editorial Universitaria. (Obra original publicada en 1927).

Hegel, G. (1968). Filosofía del Derecho (A. Mendoza, Ttrad.). Claridad. (Obra original publicada en 1837).

Hyppolite, J. (1970). Introducción a la Filosofía de la Historia de Hegel. (A. Drazul, Trad.). Ediciones Caldén. (Obra original publicada en 1948).

Honneth, A. (1997). La lucha por el reconocimiento: por una gramática moral de los conflictos sociales (M. Ballesteros, Trad.). Crítica. (Obra original publicada en 1992).

Honneth, A. (2007). Reificación: un estudio en la teoría del reconocimiento (G. Calderón, Trad.). Katz Editores. (Obra original publicada en 2005).

Honneth, A. (2010). Reconocimiento y menosprecio. Sobre la fundamentación normativa de una teoría social. J. Romeu (trad.). Buenos Aires: Katz editores.

Honneth, A. (2011). Invisibilidad sobre la epistemología moral del "reconocimiento". En La sociedad del desprecio (pp. 165-181). Trotta.

Horkheimer, M. (2006). Estado autoritario (B. Echeverría, Trad.). Ítaca. (Obra original publicada en 1983).

Ihering, R. (1905). Der Zweck Im Recht. Gale.

Lukács, G. (1970). Historia y Conciencia de Clase (F. Duque, Trad.). Editorial de Ciencias Sociales. (Obra original publicada en 1923).

Mulhall, S. (1994). Stanley Cavell: Philosophy's Recounting the Ordinary. Oxford University.

Murueta, M. (2009). Cura y Praxis. En R. Guerra y A. Yáñez (Eds.), Martín Heidegger caminos (pp. 193-199). UNAM.

Parada, J. y Castellanos, J. (2015). Trayectorias teóricas del reconocimiento moral en Axel Honneth. Revista de Antropología y Sociología: Virajes, 17(1), 57-81. http://vip.ucaldas.edu.co/virajes/downloads/Virajes17(1) 4.pdf

Pitt-Rivers, J. (1979). Antropología del honor o política de los sexos (C. Manzano, Trad.). Crítica. 
Rojas, C. (2013). La correlación sujeto/objeto en epistemología. Ceiba, 12(1), 64-72. https://revistas.upr.edu/index.php/ceiba/article/view/3488

Rorty, R. (2001). Contingencia, ironía y solidaridad (A. Sinnot, Trad.). Paidós. (Obra original publicada en 1989).

Sembler, C. (2010). La lucha por el reconocimiento y el carácter del derecho moderno Indagaciones filosófico-políticas en la Teoría Crítica [Tesis de maestría, Universidad de Chile]. Repositorio UCHILE. http://repositorio.uchile.cl/handle/2250/108596

Tello, F. (2011). Las esferas de reconocimiento en la teoría de Axel Honneth. Revista de sociología, 26, 45-57. http://doi.org/10.5354/0716-632X.2011.27487

Tomasello, M. (2007). Los orígenes culturales de la cognición humana (A. Negrotto, Trad.). Amorrortu. (Obra original publicada en 1999).

Tovar, L. (2004). Del conflicto social al conflicto moral. Aproximación a una posición política y jurídica del reconocimiento de la identidad. Revista Científica Guillermo de Ockham, 2(2), 97-108. https://doi.org/10.21500/22563202.466

Weber, M. (1964). Economía y Sociedad: Esbozo de sociología comprensiva (J. Medina, J. Roura, E. Ímaz, E. García y J. Ferrater, Trads.). Fondo de Cultura Económica. (Obra original publicada en 1922).

Winnicott, D. (1979). Escritos de pediatría y psicoanálisis (J. Beltrán, Trad.). Paidós. (Obra original publicada en 1958).

Winnicott, D. (1993). Los procesos de maduración y el ambiente facilitador (J. Piatigorsky, Trad.). Paidós. (Obra original publicada en 1965). 